\title{
PENGENDALIAN PERSEDIAAN BAHAN BAKU KARUNG PLASTIK (WOVEN) DI PT XYZ DENGAN METODE ECONOMIC ORDER QUANTITY (EOQ)
}

\author{
Suparjo $^{1}$, Rizky Sugiarto ${ }^{2}$ \\ 1,2 Jurusan Teknik Industri, Fakultas Teknologi Industri, Institut Teknologi Adhi Tama Surabaya \\ J1. Arief Rahman Hakim No.100, Klampis Ngasem, Kec. Sukolilo, Kota Surabaya, Jawa Timur 6011 \\ Email: suparjo@itats.ac.id
}

\begin{abstract}
Raw material inventory is an important factor in the production process. Lack of raw materials will result in delays in the production process, on the other hand, excess raw materials will result in swelling storage costs and other costs. Through optimal inventory control, companies can determine the right order quantity by minimizing inventory costs. The purpose of this study was to determine and analyze the raw material inventory control implemented by PT. XYZ. This type of research is quantitative descriptive by describing how the company applies raw material inventory control through the data obtained and analyzed using the Economic Order Quantity (EOQ) method. The data used are primary data in the form of analysis and interviews. From the results of the calculation of the EOQ method and the policies carried out by the company, there is a significant difference in the cost of ordering Polypropyline, Caco3, and Additives raw materials with a cost difference of 40\%. Therefore, the company can use a control strategy for ordering raw materials with the EOQ method for raw materials for Woven production that have experienced optimal expenditure compared to the strategies used by the previous company.
\end{abstract}

Keywords: Raw Material; Inventory; EOQ

\begin{abstract}
ABSTRAK
Persediaan bahan baku merupakan salah satu faktor penting dalam proses produksi. Kekurangan bahan baku akan berakibat pada terhambatnya proses produksi, sebaliknya kelebihan bahan baku akan berakibat pada membengkaknya biaya penyimpanan dan biaya lainnya. Melalui pengendalian persediaan yang optimal, perusahaan dapat menentukan kuantitas pemesanan yang tepat dengan meminimalkan biaya persediaan. Tujuan dari penelitian ini untuk mengetahui dan menganalisis pengendalian persediaan bahan baku yang diterapkan oleh PT. XYZ. Jenis penelitian ini adalah deskriptif kuantitatif dengan memaparkan bagaimana pengendalian persediaan bahan baku yang diterapkan perusahaan lewat data yang diperoleh dan dianalisis menggunakan metode Economic Order Quantity (EOQ). Data yang digunakan adalah data primer berupa hasil analisis dan wawancara. Dari hasil perhitungan metode EOQ dan kebijakan yang dilakukan perusahaan mengalami selisih biaya yang cukup banyak, pada biaya pemesanan bahan baku Polypropyline, Caco3, dan Additives dengan selisih biaya sebanyak $40 \%$. Oleh karena itu perusahaan dapat menggunakan strategi pengendalian untuk pemesanan bahan baku dengan metode EOQ untuk bahan baku produksi Woven yang mengalami pengeluaran optimal dibanding strategi yang digunakan oleh perusahaan sebelumnya.
\end{abstract}

Kata kunci: Bahan baku; persediaan; EOQ

\section{PENDAHULUAN}

Pengelolaan persediaan menentukan ukuran ekonomis dengan menyeimbangkan jumlah persediaan dan biaya pemesanannya dengan tujuan memberikan tingkat layanan tinggi dan biaya total minimal (Beck et al., 2015). Persediaan pada umumnya merupakan asset yang paling sulit dikelola 
baik untuk perusahaan dagang maupun perusahaan manufaktur (Kolias dkk., 2011). Kualitas produk juga sangat mempengaruhi tingkat kesuksesan dalam persaingan di dunia usaha. Menurut (Herawati \& Mulyani, 2016) Perhatian pada kualitas produk memberikan dampak positif kepada bisnis melalui dua cara yaitu dampak terhadap proses produksi dan dampak terhadap kualitas bahan baku. Selanjutnya perusahaan harus mampu meningkatkan kinerja, khususnya dalam proses produksi sehingga menghasilkan produk yang berkualitas dan memenuhi harapan konsumen Namun penerapan manajemen persediaan yang tidak tepat akan berdampak sangat besar terhadap keberlangsungan suatu perusahaan. Jika perusahaan membawa persediaan terlalu banyak, hal ini dapat mengikat uang di modal kerjanya (Radasanu, 2016), selain itu tingginya jumlah persediaan juga meningkatkan biaya penyimpanan, serta meningkatkan risiko terhadap kerusakan dari persediaan itu sendiri. Irwadi (2015:6) Kelangsungan proses produksi dalam suatu perusahaan akan dipengaruhi oleh beberapa faktor, antara lain: Modal, teknologi, persediaan bahan baku, persediaan barang jadi dan tenaga kerja. Persediaan (Inventory) sebagai elemen modal kerja merupakan aktiva yang selalu ada dalam keadaan berputar. Persediaan bahan baku yang cukup dapat memperlancar proses produksi serta barang jadi yang diproduksi dapat menjamin efektifitas kegiatan pemasaran, yaitu memberikan kepuasan pada pelanggan, karena apabila barang tidak tersedia maka perusahaan kehilangan kesempatan untuk merebut pasar dan perusahaan tidak dapat mensuplay barang pada tingkat optimal. Rangkuti dalam Veronika, 2013:35 menjelaskan persediaan bahan baku mempunyai kedudukan yang penting dalam perusahaan karena persediaan bahan baku sangat besar pengaruhnya terhadap kelancaran proses produksi. Herjanto (dalam Tuerah, 2014:526) menjelaskan persediaan adalah bahan atau barang yang disimpan yang akan digunakan untuk memenuhi tujuan tertentu, misalnya untuk digunakan dalam proses produksi atau perakitan, untuk dijual kembali, atau untuk suku cadang dari suatu peralatan atau mesin. Berdasarkan definisi - definisi diatas persediaan merupakan material yang dapat berupa barang mentah, barang setengah jadi, atau barang jadi yang dikelola dan digunakan guna mendukung proses produksi.Menurut Stevenson dan Chuong (2014:183), pengertian bahan baku adalah sesuatu yang digunakan untuk membuat barang jadi, bahan pasti menempel menjadi satu dengan barang jadi.Menurut Heizer dan Render (2011 : 567), titik pemesanan ulang (Reorder Point) yaitu tingkat persediaan dimana ketika persediaan telah mencapai tingkat itu, pemesanan harus dilakukan. Rangkuti (2011:83) menjelaskan bahwa pengertian Reorder Point (ROP) adalah straregi operasi persediaan merupakan titik pemesanan yang harus dilakukan suatu perusahan sehubungan dengan adanya Lead Time dan Safety Stock. Penerapan EOQ yang mampu menurunkan total biaya persediaan ini tentu telah didukung dengan beberapa penelitian sebelumnya, dan efisiensi dari EOQ tidak hanya terjadi di perusahaan manufaktur.Saputra \& Tarigan (2014) Adapun tujuan penelitian kali ini adalah dapat mengetahui frekuensi pembelian material untuk produk Woven pada PT. XYZ berdasarkan metode Ecomonic Order Quantity (EOQ), dapat mengetahui total biaya persediaan material untuk produk Woven pada PT. XYZ Industry berdasarkan metode Ecomonic Order Quantity (EOQ), dan dapat mengetahui penghematan biaya untuk produk Woven pada PT. XYZ berdasarkan metode Ecomonic Order Quantity (EOQ).

Rumusan masalah dalam penelitian ini adalah bagaimana perencanaan persediaan material untuk produk Woven yang paling optimal dalam upaya pengendalian persediaan pada PT. XYZ dengan menggunakan metode Ecomonic Order Quantity (EOQ).

Tujuan penelitian ini adalah: Dapat mengetahui frekuensi pembelian material untuk produk Woven pada PT. XYZ berdasarkan metode Ecomonic Order Quantity (EOQ), Dapat mengetahui total biaya persediaan material untuk produk Woven berdasarkan metode Ecomonic Order Quantity (EOQ), dan dapat mengetahui penghematan biaya untuk produk Woven pada PT. XYZ berdasarkan metode Ecomonic Order Quantity (EOQ).

\section{METODE PENELITIAN}

Penelitian yang dilakukan merupakan penelitian deskriptif dengan pendekatan kuantitatif. Menurut Sugiyono (2013:2) metode penelitian merupakan cara ilmiah untuk mendapatkan data dengan tujuan dan kegunaan tertentu. Sedangkan Menurut Arikunto (2013: 203) Metode penelitian adalah cara yang digunakan oleh peneliti dalam mengumpulkan data penelitian. Jenis penelitian yang digunakan dalam penelitian ini bersifat deskriptif kuantitatif yang menurut Wirartha (dalam Sarjono 
dan Kuncoro, 2014:41) yaitu menganalisis, menggambarkan dan meringkas berbagai kondisi, situasi dari berbagai data dalam bentuk angka-angka yang dikumpulkan dari hasil analisis dan wawancara atau pengamatan mengenai masalah yang diteliti yang terjadi di lapangan. Penelitian ini dilaksanakan di Pabrik PT XYZ produksi karung plastik, Proses produksi dimulai dengan peleburan bahan baku dari biji plastik dan diolah menjadi benang yang akan di jadikan karung yang berkualitas, data yang diambil dari perusahaan yaitu jumlah permintaan karung plastik 5 periode terakhir dengan menggunakan metode Economic Order Quantity (EOQ). Ada 3 bahan baku inti untuk pembuatan karung plastic ini, yaitu Polypropylene, CaCo3, Additives. Adapun teknik analisis data dengan perencanaan persediaan material untuk produk karung plastik yang paling optimal dalam upaya pengendalian persediaan bahan baku pada PT. XYZ dengan menggunakan metode Ecomonic Order Quantity (EOQ).

\section{HASIL DAN PEMBAHASAN}

Sebelum melakukan proses perencanaan dan pengendalian material suatu produk, kita harus tahu terlebih dahulu bagaimana data permintaan produk tersebut di masa lalu. Data historis inilah yang akan menjadi landasan penentuan jumlah produk yang akan diproduksi pada periode selanjutnya. Berikut adalah data forecast untuk produk Woven selama 5 bulan terakhir:

Tabel 1. Data Permintaan Produksi Woven

\begin{tabular}{|c|c|c|c|}
\hline No & Tahun & Bulan & Permintaan (pes) \\
\hline 1 & \multirow{6}{*}{2018} & Agustus & 21,416 \\
\hline 2 & & September & 21,675 \\
\hline 3 & & Oktober & 20,912 \\
\hline 4 & & November & 20,480 \\
\hline 5 & & Desember & 21,715 \\
\hline \multicolumn{2}{|c|}{ Total } & & 106,198 \\
\hline
\end{tabular}

Sumber: Manajemen PT. XYZ (2018)

Tabel 2. Penggunaan bahan baku Additives untuk produk tahun 2018

\begin{tabular}{cccc}
\hline No & Tahun & Bulan & Bahan Baku Additives (kg) \\
1 & & Agustus & 1840 \\
2 & & September & 1680 \\
3 & $2018-2019$ & Oktober & 1720 \\
4 & & November & 1850 \\
5 & & Desember & 1900 \\
& & & 8.990 \\
\hline
\end{tabular}

Sumber: Manajemen PT. XYZ (2018)

\section{Pembelian Bahan Baku}

Untuk menentukan jumlah pembelian bahan baku Polypropylene dengan 5 kali pemesanan dalam satu tahun pada perusahaan PT. XYZ dapat dihitung sebagai berikut:

$$
\begin{aligned}
& =\frac{\text { Total Kebutuhan Bahan Baku Polypropylene }}{\text { Frekuensi pemesanan dalam satu tahun }} \\
& =\frac{11.180}{5} \\
& =2.236 \mathrm{~kg}
\end{aligned}
$$

Untuk menentukan jumlah pembelian bahan baku CaCo3 dengan 5 kali pemesanan dalam satu tahun pada perusahaan PT. XYZ dapat dihitung sebagai berikut: 


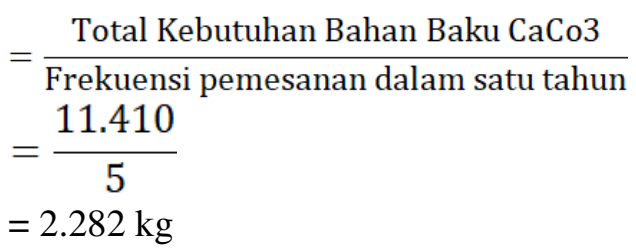

Untuk menentukan jumlah pembelian bahan baku Additive dengan 5 kali pemesanan dalam satu tahun pada perusahaan PT. XYZ dapat dihitung sebagai berikut :

$$
\begin{aligned}
& =\frac{8.990}{5} \\
& =1.798 \mathrm{~kg}
\end{aligned}
$$

\section{Total Biaya Persediaan Perusahaan}

Perhitungan total biaya persediaan Polypropylene di PT. XYZ dihitung sebagai berikut :

$$
\begin{aligned}
T I C_{\text {per }} & =(\bar{D} x H)+(n \times S) \\
& =(2.236 \times 728)+(5 \times 1.440 .000) \\
& =1.627 .808+7.200 .000 \\
T I C_{\text {per }} & =\text { Rp. } 8.827 .808,00
\end{aligned}
$$

Perhitungan total biaya persediaan CaCo3 di PT. XYZ dihitung sebagai berikut :

$$
\begin{aligned}
T I C_{\text {per }} & =(\bar{D} x H)+(n x S) \\
& =(2.282 \times 713)+(5 \times 1.440 .000) \\
& =1.627 .066+7.200 .000 \\
T I C_{\text {per }} & =\text { Rp. } 8.827 .066,00
\end{aligned}
$$

Perhitungan total biaya persediaan Additive di PT. XYZ dihitung sebagai berikut :

$$
\begin{aligned}
T I C_{\text {per }} & =(\bar{D} x H)+(n x S) \\
& =(1.798 \times 906)+(5 \times 1.440 .000) \\
& =1.628 .988+7.200 .000 \\
T I C_{\text {per }} & =\text { Rp. } 8.828 .988,00
\end{aligned}
$$

\section{Metode EOQ}

berikut:

Hal-hal yang harus diperhitungan dalam menggunakan metode EOQ ini adalah sebagai

Polypropyline

Pembelian bahan baku Polypropyline yang ekonomis $\left(\mathrm{Q}^{*}\right)$

Pembelian bahan baku yang ekonomis ini didasarkan pada:

- Total kebutuhan bahan baku Polypropylene(D) $\quad=11.180 \mathrm{~kg}$

- Biaya pemesanan sekali pesan (S) = Rp. 1.440 .000

- Biaya simpan per unit $(\mathrm{H}) \quad=\mathrm{Rp} .728$

Maka setelah diketahui hal seperti yang tercantum diatas, besarnya pembelian bahan baku yang ekonomis menggunakan metode EOQ adalah sebagai berikut:

$$
\begin{aligned}
& \mathrm{Q}=\sqrt{\frac{2 \mathrm{D} \mathrm{S}}{\mathrm{H}}} \\
& \mathrm{Q} *=\sqrt{\frac{2 \times 11.180 \times 1.440 .000}{728}} \\
& \mathrm{Q} *=6.650,46 \mathrm{~kg}
\end{aligned}
$$

Frekuensi pemesanan bahan baku (F)

Dengan menggunakan metode EOQ dapat dihitung jumlah pemesanan dalam satu tahun atau sering disebut frekuensi pembelian dapat dihitung sebagai berikut :

$$
F=\frac{D}{Q *}
$$




$$
\begin{aligned}
& F=\frac{11.180}{6.650,46} \\
& F=1,68 \approx 2 \text { kali }
\end{aligned}
$$

Jadi frekuensi pemesanan bahan baku menurut metode EOQ adalah paling sering pada bahan baku Polypropylene yaitu 2 kali dalam 5 bulan.

Total biaya persediaan (TIC)

Agar dapat menghitung biaya persediaan maka terlebih dahulu diketahui:

- Total kebutuhan bahan baku (D)

$$
=11.180 \mathrm{~kg}
$$

- Biaya pemesanan sekali pesan (S) = Rp. 1.440 .000

- Biaya simpan per unit $(\mathrm{H}) \quad=$ Rp. 728

- Pembelian bahan baku yang ekonomis $\left(Q^{*}\right)=6.650,46 \mathrm{~kg}$

$$
\text { TIC }=\left[\frac{D}{Q *} S\right]+\left[\frac{Q *}{2} H\right]
$$

$$
\begin{aligned}
T I C & =\left[\frac{11.180}{6.650,46} 1.440 .000\right]+\left[\frac{6.650,46}{2} 728\right] \\
T I C & =[2.420 .764,88]+[2.420 .767,44] \\
T I C & =R p 4.841 .532,32
\end{aligned}
$$

Jadi total biaya persediaan bahan baku pada PT. XYZ menggunakan metode EOQ sebesar Rp. 4.841.532,32 pada setiap kali melakukakan pemesanan bahan baku Polypropyline.

$\mathrm{CaCo} 3$

Pembelian bahan baku CaCo3 yang ekonomis ini didasarkan pada :

- Total kebutuhan bahan baku CaCo3 (D) $\quad=11.410 \mathrm{~kg}$

- Biaya pemesanan sekali pesan (S) = Rp. 1.440 .000

- Biaya simpan per unit $(\mathrm{H}) \quad=\mathrm{Rp} .713$

Maka setelah diketahui hal seperti yang tercantum diatas, besarnya pembelian bahan bahan baku yang ekonomis menggunakan metode EOQ adalah sebagai berikut:

$$
\begin{aligned}
& \mathrm{Q} *=\sqrt{\frac{2 \mathrm{D} \mathrm{S}}{\mathrm{H}}} \\
& \mathrm{Q} *=\sqrt{\frac{2 \times 11.410 \times 1.440 .000}{713}} \\
& \mathrm{Q} *=6.788,82 \mathrm{~kg}
\end{aligned}
$$

Frekuensi pemesanan bahan baku $(\mathrm{F})$

Dengan menggunakan metode EOQ dapat dihitung jumlah pemesanan dalam satu tahun atau sering disebut frekuensi pembelian dapat dihitung sebagai berikut :

$F=\frac{D}{Q *}$

$$
F=\frac{11.410}{6.788,82}
$$

$F=1,68 \approx 2$ kali

Jadi frekuensi pemesanan bahan baku menurut metode EOQ adalah paling sering pada bahan baku $\mathrm{CaCo} 3$ yaitu 2 kali dalam 5 bulan.

Total biaya persediaan (TIC)

Agar dapat menghitung biaya persediaan maka terlebih dahulu diketahui:

- Total kebutuhan bahan baku (D)

- Biaya pemesanan sekali pesan (S)

- Biaya simpan per unit $(\mathrm{H})$

$$
\begin{gathered}
=11.410 \mathrm{~kg} \\
=\text { Rp. } 1.440 .000
\end{gathered}
$$$$
=\text { Rp. } 713
$$ 
- Pembelian bahan baku yang ekonomis $\left(\mathrm{Q}^{*}\right)=6.788,82 \mathrm{~kg}$

$$
\begin{aligned}
\text { TIC } & =\left[\frac{D}{Q *} S\right]+\left[\frac{Q *}{2} H\right] \\
\text { TIC } & =\left[\frac{11.410}{6.788,82} 1.440 .000\right]+\left[\frac{6.788,82}{2} 713\right] \\
T I C & =[2.420 .214,41]+[2.420 .214,33] \\
T I C & =R p 4.840 .428,74
\end{aligned}
$$

Jadi total biaya persediaan bahan baku pada PT. XYZ menggunakan metode EOQ sebesar Rp 4.840.428,74 pada setiap kali melakukakan pemesanan bahan baku CaCo3.

Additive

Pembelian bahan baku Aditive yang ekonomis ini didasarkan pada:

- Total kebutuhan bahan baku aditive (D) $\quad=8.990 \mathrm{~kg}$

- Biaya pemesanan sekali pesan (S) = Rp. 1.440 .000

- Biaya simpan per unit $(\mathrm{H}) \quad$ = Rp. 906

Maka setelah diketahui hal seperti yang tercantum diatas, besarnya pembelian bahan baku yang ekonomis menggunakan metode EOQ adalah sebagai berikut:

$$
\begin{aligned}
& \mathrm{Q} *=\sqrt{\frac{2 \mathrm{D} \mathrm{S}}{\mathrm{H}}} \\
& \mathrm{Q} *=\sqrt{\frac{2 \times 8.990 \times 1.440 .000}{906}} \\
& \mathrm{Q} *=5.345,79 \mathrm{~kg}
\end{aligned}
$$

Frekuensi pemesanan bahan baku $(\mathrm{F})$

Dengan menggunakan metode EOQ dapat dihitung jumlah pemesanan dalam satu tahun atau sering disebut frekuensi pembelian dapat dihitung sebagai berikut :

$$
F=\frac{D}{Q *}
$$

$$
F=\frac{8.990}{5.345,79}
$$

$F=1,68 \approx 2$ kali

Jadi frekuensi pemesanan bahan baku menurut metode EOQ adalah paling sering pada bahan baku Additiv yaitu 2 kali dalam 5 bulan.

Total biaya persediaan (TIC)

Agar dapat menghitung biaya persediaan maka terlebih dahulu diketahui:

- Total kebutuhan bahan baku(D)

- Biaya pemesanan sekali pesan (S)

- Biaya simpan per unit $(\mathrm{H})$

$$
=8.990 \mathrm{~kg}
$$

- Pembelian bahan baku yang ekonomis $\left(\mathrm{Q}^{*}\right)=5.345,79 \mathrm{~kg}$

$$
\begin{aligned}
\text { TIC } & =\left[\frac{D}{Q *} S\right]+\left[\frac{Q *}{2} H\right] \\
T I C & =\left[\frac{8.990}{5.345,79} 1.440 .000\right]+\left[\frac{5.345,79}{2} 906\right] \\
T I C & =[2.421 .643,94]+[2.421 .642,87] \\
\text { TIC } & =R p 4.843 .286,81
\end{aligned}
$$

Jadi total biaya persediaan bahan baku pada PT. XYZ menggunakan metode EOQ sebesar Rp. 4.843.286,81 pada setiap kali melakukakan pemesanan bahan baku Additiv. 


\section{Perbandingan Hasil}

Tabel 3. Perbandingan Bahan Baku Produksi Sekali Pesan

\begin{tabular}{lcc}
\hline \multicolumn{1}{c}{ Produk } & Kebijakan Perusahaan & EOQ \\
\hline Polypropylene & $2.236 \mathrm{~kg}$ & $6.650,46 \mathrm{~kg}$ \\
Caco3 & $2.282 \mathrm{~kg}$ & $6.788,82 \mathrm{~kg}$ \\
Additives & $1.798 \mathrm{~kg}$ & $5.345,79 \mathrm{~kg}$ \\
\hline
\end{tabular}

Tabel 4. Perbandingan Biaya Pemesanan Bahan Baku

\begin{tabular}{lll}
\hline \multicolumn{1}{c}{ Bahan Baku } & $\begin{array}{c}\text { TIC menurut } \\
\text { Perusahaan }\end{array}$ & TIC menurut EOQ \\
\hline Polypropyline & Rp. $8.827 .808,00$ & $R p 4.841 .532,32$ \\
Caco3 & Rp. $8.827 .066,00$ & $R p 4.840 .428,74$ \\
Additives & Rp. $8.828 .988,00$ & $R p 4.843 .286,81$ \\
\hline
\end{tabular}

\section{KESIMPULAN}

Jumlah pemesanan produksi dari perusahaan maupun perhitungan EOQ. Adapun perusahaan melakukan pemesanan kembali bahan baku setiap $2.236 \mathrm{~kg}$ Polypropyline, $2.282 \mathrm{~kg}$ Caco3, $1.798 \mathrm{~kg}$ Additives. Terlihat perbedaan dalam pemesanan bahan baku produksi, dari hasil metode EOQ pemesanan bahan baku lebih banyak dari kebijakan perusahaan yaitu $6.650,46 \mathrm{~kg}$ Polupropyline, $6.788,82 \mathrm{~kg} \mathrm{Caco} 3,5.345,79 \mathrm{~kg}$ Additives, dengan melakukan pesanan lebih banyak akan menghemat biaya pemesanan yang dilakukan berulang-ulang

Dari tabel diatas dapat dilihat bahwa perbedaan pengeluaran biaya untuk pemesanan bahan baku produksi Woven, hasil perhitungan metode EOQ dan kebijakan yang dilakukan perusahaan mengalami selisih biaya yang cukup banyak, pada biaya pemesanan bahan baku Polypropyline, Caco3, dan Additives dengan selisih biaya sebanyak $40 \%$. Oleh karena itu perusahaan dapat menggunakan strategi pengendalian untuk pemesanan bahan baku dengan metode EOQ untuk bahan baku produksi Woven yang mengalami pengeluaran optimal dibanding strategi yang digunakan oleh perusahaan sebelumnya.

\section{DAFTAR PUSTAKA}

Beck, Fabian G., Eric H Grosse, dan Teßmann Ruben. (2015). An Extention for Dynamic Lot-sizing Heuristics. Production and Manufacturing Research, 3(1), pp: 20-35.

Heizer, J., dan Render, B. (2011) . Manajemen Operasi. Edisi Kesembilan, Buku 1. Salemba Empat, Jakarta.

Herawati, H., \& Mulyani, D. (2016). Pengaruh Kualitas Bahan Baku dan Proses Produksi Terhadap Kualitas Produk pada Ud. Tahu Rosydi Puspan Maron Probolinggo. Prosiding Seminar Nasional, 463-482. Retrieved from

Irwadi, M. (2015). Penerapan Reorder Point Untuk Persediaan Bahan Baku Produksi Alat Pabrik Kelapa Sawit Pada PT. Swakarya Adhi Usaha Kabupaten Bayuasin. Jurnal Akuntansi Politeknik Sekayu (ACSY), Vol. II, No.1, Maret 2015.

Kolias, Georgios D., Demelis Shopia P., dan Filios Vasilios P. (2011). An Empirical Analysis of Inventory Turnover Behaviour in Greek Retail Sector: 2000-2005. Int. Journal Production Economics, 133, pp: 143-153.

Radasanu, Alin Constantin. (2016). Inventory Management, Service Level and Safety Stock. Journal of Public Administration, Finance and Law, 9, pp: 145-153.

Rangkuti, F. (2011). Riset Pemasaran. PT. Gramedia Pustaka Utama, Jakarta. 
Saputra, Prasetya Halim dan Zeplin J.H. Tarigan.(2014). Analisa Deskriptif Manajemen Persediaan pada PT. Usman Sinar Bulan Sidoarjo. Jurnal Agora Universitas Kristen Petra, 2(2)

Sarjono, H., dan Kuncoro, E. A. (2014). Analisis Perbandingan Perhitungan Reorder Point. Binus Business Review. Vol. 5 No. 1 Mei 2014: 288-300.

Stevenson, W.J., dan Chuong, S.C. (2014), Manajemen Operasi Perspektif Asia. Edisi Sembilan. Buku 2. Salemba Empat, Jakarta.

Sugiyono. (2013). Metode Penelitian Kombinasi (Mixed Methods). Cetakan Ketiga. Alfabeta, Bandung.

Tuerah, M. C. (2014). Analisis Pengendalian Persediaan Bahan Baku Ikan. Tuna Pada CV. Golden KK. Jurnal EMBA. ISSN 2303-1174. Vol.2 No.4, 524. Manado. 